\title{
AN EDUCATIONAL DEPLOYMENT OF THE NCAR MOBILE INTEGRATED SOUNDING SYSTEM
}

Brian Billings, Stephen A. Cohn, Rodney J. Kubesh, and William O. J. Brown

A versatile NCAR instrument platform allowed for maximum educational benefits from two relatively short deployments.

H ands-on experiential learning has strong benefits and is emphasized at many universities. Roebber (2005) presented interview results with undergraduate meteorology majors throughout the department and most of the interviewees preferred active learning styles "where information is processed through engagement in applications or discussion." (Roebber 2005, p. 509) Similar positive

AfFILIATIONS: BiLlings*-Meteorology Program, Department of Earth Sciences, Millersville University of Pennsylvania, Millersville, Pennsylvania; COHN-National Center for Atmospheric Research, and Hyperloop Advanced Research Partnership, Boulder, Colorado; KUBESH-Department of Atmospheric and Hydrologic Sciences, St. Cloud State University, St. Cloud, Minnesota; BrowN-National Center for Atmospheric Research, Boulder, Colorado

*CURRENT AFFILIATION: BILlings-Doane University, Crete, Nebraska

CORRESPONDING AUTHOR: Brian Billings,

brian.billings@doane.edu

The abstract for this article can be found in this issue, following the table of contents.

DOI:10.II75/BAMS-D-17-0185.I

In final form 27 September 2018

(C)2019 American Meteorological Society

For information regarding reuse of this content and general copyright

information, consult the AMS Copyright Policy. feedback has been obtained through surveys from individual courses or programs using this philosophy. Some of these have been conducted remotely, such as severe weather field courses or training activities in Tornado Alley at the University of North Carolina at Asheville (UNC-Asheville; Godfrey et al. 2011) and the U.S. Naval Academy (Barrett and Woods 2012); a University of Wisconsin-Milwaukee study abroad course in Mexico City, Mexico (Kahl and Cerón 2014); and Mount Washington Observatory's summer internship program (Kelsey et al. 2015). Other examples have been on campus, but they have been based around a large instrument facility, an S-band radar in the case of Hopper et al. (2013), or used smaller instruments in a problem-solving scenario called a "consulting classroom" (Croft and Ha 2014).

The preceding references and those that follow in this section are in line with the 2009 Unidata Users Workshop, which emphasized that engagement "can be enhanced through the use of instrumentation and observations" (Etherton et al. 2011, p. 478). However, gaining student access to instruments and to expertise in their operation can be difficult, especially for smaller undergraduate programs. Fortunately, there

Publisher's Note: This article was revised on 20 June 2019 to correctly note that the Mexico City, Mexico, study abroad program is offered through the University of Wisconsin-Milwaukee. 
are several methods for such programs to still achieve this goal. Each has advantages and disadvantages, so it is valuable to invest in all of them.

Smaller groups of students can travel to locations where high-quality instruments are available to them, such as research stations or large field experiments. Examples of research stations that have a long history of supporting education are Storm Peak Laboratory atop the Continental Divide in Colorado (Borys and Wetzel 1997) and the Colorado State UniversityUniversity of Chicago-Illinois State Water Survey (CSU-CHILL) radar facility (Brunkow et al. 2000). Students may also conduct observational work as part of educational programs like Significant Opportunities in Atmospheric Research and Science (SOARS; Windham et al. 2004).

Student involvement in large field experiments nearly always has educational benefits. For example, Rauber et al. (2007) describe students' experiences during Rain in Cumulus over the Ocean (RICO), in which they designed and carried out a special intensive observing period (IOP) using sophisticated project assets. Other examples include Evans et al. (2012), who describe contributions by graduate students and postdoctoral researchers during Pre-Depression Investigation of Cloud-systems in the Tropics (PREDICT), and Kristovich et al. (2017), who describe undergraduate and graduate support during the Ontario Winter LakeEffect Systems (OWLeS) project. The latter included forecasting as well as operating and maintaining instrument platforms in extreme weather conditions.

Such travel will usually be possible only for a small fraction of a program's students. Another option is for a department to obtain equipment that can be used by all students. Even low-cost investments can provide great value, such as the rotating tanks described by Illari et al. (2009). Other possibilities include webcams (Brunskill and Jones 2011), rapidly deployable surface stations (Schroeder and Weiss 2008), and small unmanned aircraft (Houston et al. 2012). Cassano (2014) described a bicycle-mounted weather station adaptable for classroom use. Despite the range of lower-cost instruments and platforms available, there is much to be gained when students work with more advanced equipment.

Several programs have obtained advanced equipment through creative use of external funding. Examples include multi-institution collaboration (Biggerstaff et al. 2005), incremental addition of platform components (Knupp et al. 2000), and federal surplus programs (Shapiro et al. 2009). These methods are also feasible for smaller undergraduate meteorology programs.
Yet even a well-equipped atmospheric science program can benefit from access to additional research instrumentation to provide varied learning experiences. Increasingly, courses and departments are arranging short-term visits by transportable or mobile observational research platforms. While this can be arranged through means such as collaboration, a convenient and effective path for students to gain hands-on experience with research instrumentation is through the National Science Foundation (NSF) Educational Deployment Program (EDP).

NSF EDP. NSF offers a subset of their Lower Atmosphere Observing Facilities (LAOF) to be deployed for educational purposes. A portion of the NSF LAOF Deployment Pool is set aside for these educational efforts at no cost to the requestor. From its inception in 2008 through the end of fiscal year 2017, the NSF has funded 55 educational deployments.

The NSF LAOF are managed and maintained by three partner organizations, including the National Center for Atmospheric Research (NCAR) Earth Observing Laboratory, the Center for Severe Weather Research (CSWR), and the University of Wyoming (UW). Each partner organization provides a subset of their LAOF resources for educational deployments. The NCAR Earth Observing Laboratory is the major provider of the LAOF in support of atmospheric research, both through development and deployment of facilities and subsequent quality control and curation of the data. The EOL also manages the EDP request process on behalf of the NSF. According to the EOL website (www.eol.ucar.edu/educational -deployments), the educational deployments are "designed to expose bright young college students in science and engineering to observational meteorology, without requiring faculty to design and propose a full-scale scientific field campaign." Deployment cost is usually limited to $\$ 25,000$, typically resulting in a deployment of three weeks or less.

Faculty proposals have been dominated by requests for one of CSWR's Doppler on Wheels (DOW; Wurman et al. 1997), which now exist in several forms, including a rapid-scan version. Milrad and Herbster (2017) review several previous DOW educational requests and list 32 such deployments between 2008 and 2016. The frequency of DOW requests is likely due to several factors, including the easy integration into a course on radar meteorology, student familiarity through the media, and its use in educational outreach prior to the current NSF program, such as at The Pennsylvania State University from 2003 to 2005 as described by Richardson et al. (2008). 
TABLE I. EOL educational deployments of facilities other than Doppler on Wheels. GAUS: GPS Advanced Upper-Air Sounding System. ARTSE: Atmospheric Response to a Total Solar Eclipse.

\begin{tabular}{|lccc|}
\hline Project ID & Semester & Host university & Facility \\
\hline EDUCT & Spring 2009 & University of Virginia & MISS \\
CWEX & Summer 2011 & lowa State University & ISFS \\
BaSE CaMP I/II & Fall 2012 and 2014 & St. Cloud State University & MISS \\
START & Spring 2014 & Embry-Riddle Aeronautical University & UWKA \\
CABL & Spring 2015 & University of Colorado Boulder & ISFS/GAUS \\
BASS & Summer 2015 & University at Oswego, State University of New York & CSWR pods \\
ARTSE & Summer 2017 & Columbus State University & ISFS \\
SEAR-MAR & Fall 2017 & Millersville University and others & UWKA \\
\hline
\end{tabular}

Operating in the $\mathrm{X}$ band, the DOWs require active weather conditions to obtain useful radar measurements, and the probability of these occurring during a short deployment varies with a project's focus and location. Toth et al. (2011) used their deployment to examine the effect of wind turbines on radar observations, which is relevant in meteorological situations with even weak wind. Milrad and Herbster (2017) used their radar observations for scientific objectives related to the Florida sea breeze, a reliably occurring feature during its May deployment period. Similarly, Bell et al. (2015) brought a DOW to Hawaii for the first time, where 10 cloud and precipitation events were sampled in this humid environment over a 20-day period.

While DOWs are highly requested, the subset of available LAOF includes other instrument platforms that not only provide variety to the student learning experience but also obtain data in a greater range of weather conditions. These instruments have been underutilized given their success in the previous requests listed in Table 1. CSWR also provides deployable weather pods, which were used without a DOW unit in the Boundaries across Severe Storms (BASS) project. Rajewski et al. (2013) used four surface flux stations from EOL's Integrated Surface Flux System (ISFS) as part of the Crop Wind Energy Experiment (CWEX). ISFS equipment was also used in Characterizing the Atmospheric Boundary Layer (CABL) as part of a larger field experiment on boundary layer meteorology (Lundquist et al. 2017). Last, in special cases the maximum grant size can be waived to allow deployment of the University of Wyoming King Air (UWKA). This first occurred in 2014 for Student Training in Airborne Research and Technology (START; www.eol.ucar.edu/field_projects/start-eo), which consisted of 10 flights in the Prescott, Arizona, area. An even larger-scale experiment, the Student Experience in Airborne Research in the Mid-Atlantic Region (SEAR-MAR) King Air deployment in 2017, was led by Millersville University, but it also included three other area institutions and a variety of ground instrumentation to supplement the research flights (Capella and Morehead 2018).

MISS. The most versatile facility that can be requested by universities is the EOL Atmospheric Profiling Group's Integrated Sounding System (ISS; Parsons et al. 1994). The Mobile ISS (MISS) has instruments and operating computers mounted on a flatbed trailer. Its portability and suite of four or more complex instruments make it ideal for educational field projects.

First, a 915-MHz radar obtains wind profiles using Doppler beam swinging. Operating in the UHF band, returns can come from humidity and temperature gradients resulting from turbulent mixing, meaning that data are obtained in all but the driest of conditions. With precipitation, even more data are obtained from hydrometeor backscatter, with the vertical Doppler velocity and spectral width dominated by the hydrometeor fall speed. Wind profiles in these conditions can reach to midlevels, but even clear-air profiles typically provide data up to $3 \mathrm{~km}$.

The wind profiler is also part of a radio acoustic sounding system (RASS) that obtains vertical temperature profiles by tracking the speed of sound signals. These are produced by two large acoustic speakers transported with the MISS and placed next to the radar during operations (Fig. 1). Measurements are again obtained for many clear-air conditions, though precipitation, high winds, and cold air will 
result in lower quality. Also, because of the loud volume, care must be taken to operate RASS only at locations sufficiently far from residential and business property.

MISS also carries radiosonde ${ }^{1}$ equipment, including the balloons and helium. Radiosondes are particularly suited to university visits, since students can perform many hands-on steps. Even those just attending a launch are more engaged because of how much can be observed, from preflight preparations to the balloon's final disappearance from sight. Radiosondes can be launched in nearly all weather conditions, so they are a useful, reliable source of interesting data even in shorter deployment projects.

MISS also carries a modified Vaisala WXT510 surface weather station that provides valuable data and educational opportunities. Students can work with its two-dimensional sonic anemometer and an acoustic rain gauge with reporting modes, including tipping-

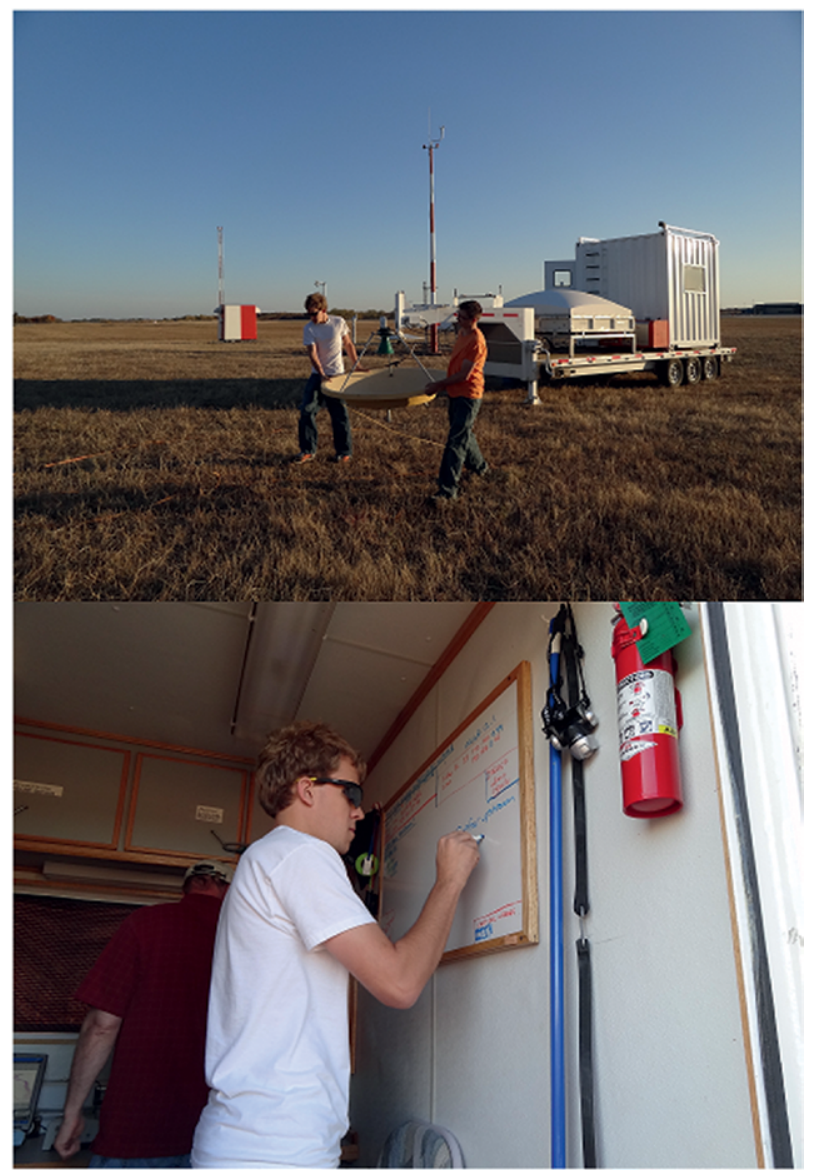

FIG. I. (top) Students relocate MISS's RASS speakers. The wind profiler and enclosure for the computers are visible on the trailer in the background, as well as the KSTC ASOS station. (bottom) Inside MISS, students record the speaker locations for a signal strength sensitivity experiment. bucket accumulation and disdrometer size counts. The station's smaller size allows quick deployment in rapidly changing weather and also allows students access to all the sensors. This station is also used to check the initial radiosonde quality and provides an anchor data point for the MISS profiling instruments.

Educational outreach with ISS preceded the NSF Educational Deployment Program. In 1994, an ISS supported the Instrumentation course at the University of Nevada, Reno (Cohn et al. 1997), and focused on observing strong inversions that form most nights in the Reno Basin. Students learned about complex instruments with hands-on experience, and the observations drove numerical simulations used by modeling students. Students also had presentation opportunities, with some producing conference papers. For the course in 2002, two ISSs were deployed to the basin and observed a variety of weather phenomena, including a dust storm (Cohn et al. 2006).

The first request of MISS as an EOL educational deployment was for the Education in Complex Terrain Meteorology (EDUCT) program at the University of Virginia in April 2009. MISS was based with other university instruments in the mountainous Shenandoah National Park. The radiosonde observations from this project were used by Lee and De Wekker (2016) to evaluate a method for determining PBL heights in valleys from nearby airport soundings.

In fall 2012, St. Cloud State University (SCSU) requested a 1-week MISS deployment. SCSU previously used a DOW for Northern Autumn Plains Echo Patterns (NAPEP; www.eol.ucar.edu/field_projects Inapep) in October 2010, a favorable month for frontal passages, but it had only one precipitation day. To increase the likelihood of success in the 2012 deployment, objectives were set for many weather conditions, including boundary layers and frontal passages. The deployment was named Boundary Structure Experiments with Central Minnesota Profiling (BaSE CaMP I; www.eol.ucar.edu/field_projects/base-camp-i). BaSE CaMP II was a longer fall 2014 deployment (www.eol.ucar.edu/field_projects/base-camp-ii). This article focuses on the methods for achieving each project's educational goals, namely: i) providing as many opportunities as possible for students to participate in hands-on field research, ii) collecting a diverse dataset for future use in multiple curriculum courses and student research projects that lead to future presentation opportunities, and iii) increasing awareness

\footnotetext{
${ }^{1}$ Since wind measurements are obtained by GPS tracking, the instruments are also rawinsondes.
} 
TABLE 2. IOPs during the mobile deployment phases of each project. AWS: automatic weather station.

\section{BaSE CaMP I}

\begin{tabular}{|lcccc|}
\hline ID & Time and date & Location & Experiment & Soundings \\
\hline Alpha & 1230-1700 UTC 29 Sep 2012 & Sauk River Valley & Cold pool breakup \\
Beta & 2200 UTC I Oct 2012 & St. Cloud Regional Airport & Balloon tracking and RASS \\
Charlie & 2200-2230 UTC 2 Oct 2012 & KVSC radio tower & Comparison/combined profiles \\
Delta, Echo & 0000-1400 UTC 4 Oct 2012 & SCSU parking lot Q & Frontal passage/AWS \\
Foxtrot & 0000 UTC 6 Oct 2012 & SCSU parking lot Q & Trace graupel event & 2 \\
\hline
\end{tabular}

BaSE CaMP II

\begin{tabular}{|lcccc|}
\hline ID & Time and date & Location & Experiment & Soundings \\
\hline Alpha & $1800-2100$ UTC 16 Oct 2014 & KVSC radio tower & Comparison/combined profiles \\
Bravo & $1230-1700$ UTC 18 Oct 2014 & Sauk River valley & Along-valley flow \\
Charlie & 2100 UTC 20 Oct 2014 & $\begin{array}{c}\text { SCSU MN Highway Safety } \\
\text { and Research Center }\end{array}$ & Radiosonde launch training \\
Delta & I600 UTC 21 Oct 2014 & SCSU South Campus & Urban flows \\
Echo & I600 UTC 22 Oct 2014 & $\begin{array}{c}\text { SCSU MN Highway Safety } \\
\text { and Research Center }\end{array}$ & RASS tests \\
\hline
\end{tabular}

of SCSU and EOL activities in the local educational and regional and national operational communities.

MOBILE DEPLOYMENTS. BaSE CaMP I and BaSE CaMP II targeted a wide range of weather. Given the long-range unpredictability of specific events, the plan for the 8-day BaSE CaMP I period was to take advantage of MISS mobility by frequently relocating to preselected sites suitable for forecasted events. BaSE CaMP II was longer, a month in duration, and organized with one week of mobile deployments for the same purpose, followed by a longer period at a fixed site. This section describes these mobile deployments and the most significant educational outcomes. Table 2 lists key characteristics of the deployments.

Structure and flow in complex terrain. Mountain meteorology is excellent for learning because interesting situations develop in a wide range of synoptic conditions. Pressure gradients and flows can be quiescent or strong; air can be moist or dry. The northern sidewall of central Minnesota's Sauk River valley provided steep terrain for the projects. Both years, the Munson Township Hall (near Richmond, Minnesota, and about $30 \mathrm{~km}$ west-southwest of St. Cloud, Minnesota, on MN 23) was rented to provide a base and Wi-Fi access for MISS and the students.
Each year, an early Saturday morning was chosen for the Munson IOP to attract students who had evening job commitments.

During BaSE CaMP I, a closed 500-hPa high was forecast over the area, allowing for the study of the undisturbed breakup of a valley cold pool. The plan was to release four radiosondes at 90 -min intervals starting near sunrise at 1230 UTC [0730 local daylight time (LDT)] 29 September 2012. Figure 2a shows students launching this balloon. The resulting skew $T$ profile (Fig. $2 \mathrm{~b})$ captures the very strong $\left(14^{\circ} \mathrm{C}\right)$ and shallow $(660 \mathrm{~m})$ inversion of the cold pool.

To expand the field observations beyond MISS, and to increase student exposure to measurements and field work, students were given handheld Kestrel anemometers and maps of the valley. They selected several observation points, including along a road ascending the 50-m-high valley sidewall, and measured temperature and wind. On returning to the township hall for the second radiosonde launch, students were excited to report that their measurement matched the inversion they had seen in the first radiosonde profile.

Other activities between launches included touring MISS in small groups, checking regional observations for spatial context of the event, and comparing MISS's surface station with a vehicle-mounted observing system owned by one of the students. Later in 
the morning, students gained experience with RASS operations when that instrument began to provide temperature soundings. The IOP lasted long enough to produce a final skew $T$ with the inversion entirely eroded (Fig. 2d). Ten students participated in the Saturday IOP, which was the largest number to attend any of the field measurement activities.

Pilot balloon and RASS experiments. RASS is loud and preferably not operated near occupied buildings, so a BaSE CaMP I MISS deployment to the St. Cloud Regional Airport offered the chance for students to operate and study this instrument. Students at this location also visited the adjacent National Weather Service (NWS) Automated Surface Observing Systems (ASOS) facility and attempted to track a radiosonde by triangulating a pair of bearing and elevation angle measurements recorded from visual observations. Students in the Synoptic Meteorology class chose the day for deployment, identifying 1 October 2012 as the windiest day in a 3-day period. Their analysis and outcome was highlighted in a presentation during the current Weather Analysis course.

The radiosonde tracking experiment was first. Time, heading, and elevation observations were made by students with Brunton compasses at two spots separated by a baseline of $150 \mathrm{ft}(\approx 46 \mathrm{~m})$. Unfortunately, the compasses required rotation between reading the elevation and heading angles, causing the fast-moving balloon to be repeatedly lost from the observer's view. Ultimately, calculations and comparison with GPS were not performed because of data quality concerns, but students still enjoyed making the attempt and the specific instrument issue was noted for future improvement.

Routine RASS observations were made and the physics behind this remote sensor was explained. The highlights of the afternoon were hands-on experiments to study the RASS performance. Students relocated the acoustic speakers to test the effect on signal quality, since the sound waves must propagate into the vertically pointing radar beam. From their original location, the speakers were moved varying distances

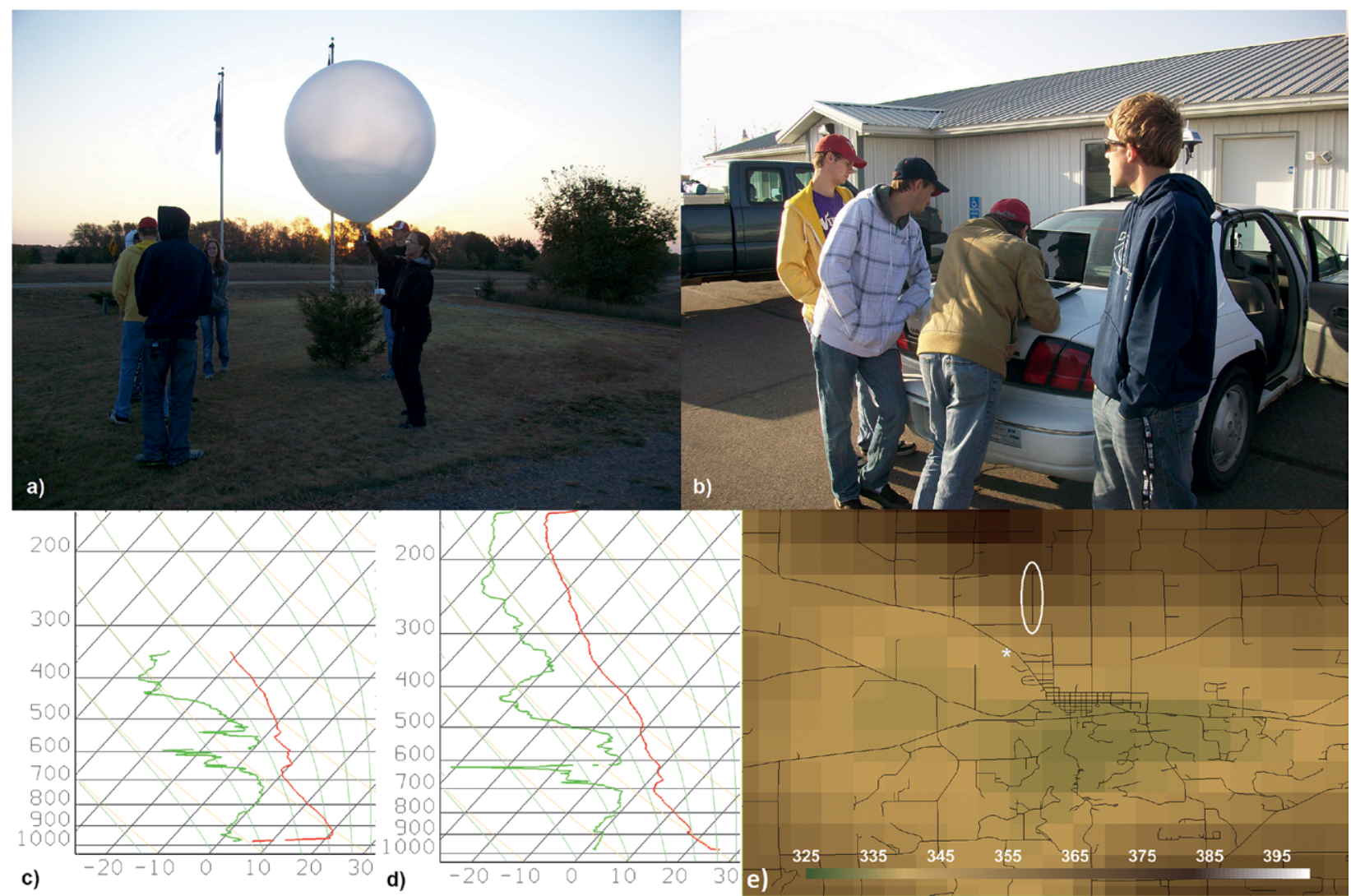

FIG. 2. IOP Alpha. (a) The I230 UTC radiosonde is launched at the start of solar heating. (b) Students examine real-time online data between launches. Skew T diagram for (c) I230 and (d) I700 UTC 29 Sep 20 I2. (e) Topography (m MSL) of the Sauk River valley near Richmond. The location of MISS is marked by an asterisk, while the road used by the students is circled. 


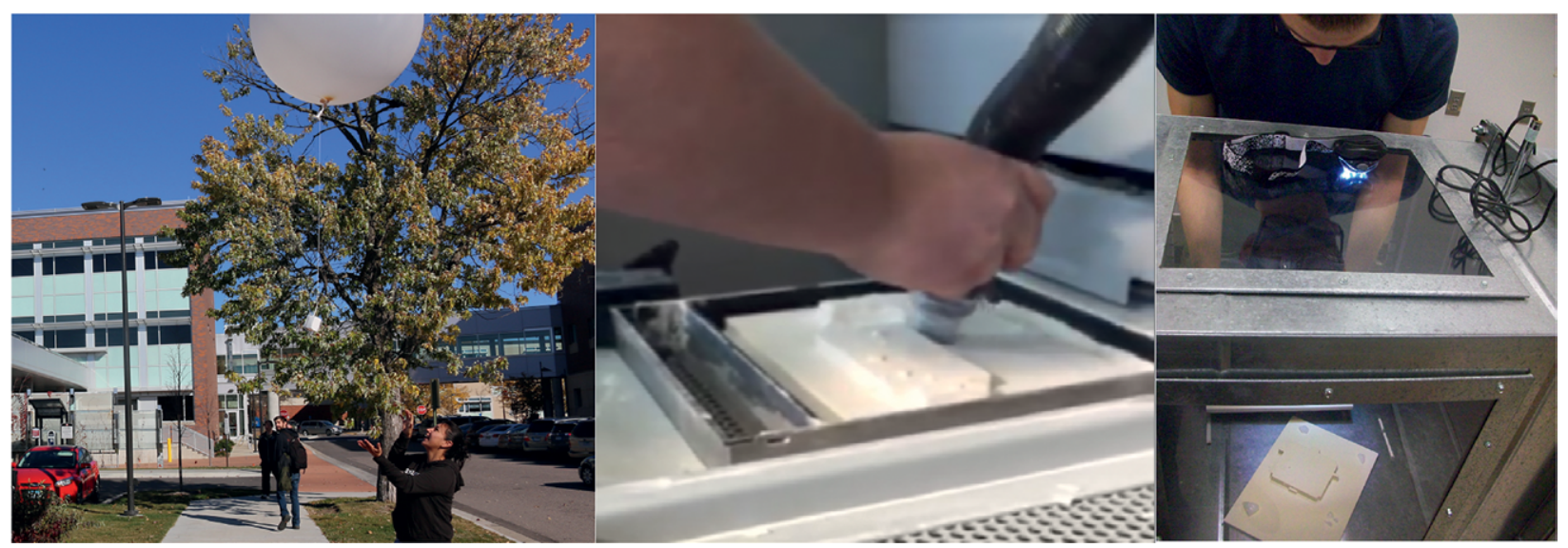

FIG. 3. (left) One radiosonde was launched for IOP Delta at an on-campus location. A physical model of the building seen on the left side was created to study airflow. (middle) The excess plaster is cleaned from around this model, and (right) the model is later tested in SCSU's wind tunnel.

farther upstream of MISS's radar (Fig. 1). Based on the height of the resulting temperature profile, there was an improvement with upstream locations. With the speakers back in their original location, the next routine profile was also higher, indicating that temporal effects may also have been important.

A second experiment involved replacing the normal RASS audio file (a random sequence of tones filling an audio frequency band) with music from students' phones. If useful temperature profiles could be measured using music rather than "noise," this would be an improvement for anyone operating the site. None of the songs resulted in usable data. The students did suggest that selections with more soprano might have been more successful, which shows good understanding of the RASS remote sensing concept.

Tower measurement comparisons and composites. The SCSU meteorology program maintains instruments at three heights on the 150-m (St. Cloud) KVSC radio tower. Both years, MISS was deployed near the tower, which provided applications for these data. First, tower observations could be compared with radiosonde launches. Second, since the MISS radar's lowest range gate is $150 \mathrm{~m}$, the tower measurements would fill in the gap below, resulting in a more complete wind profile.

In BaSE CaMP I, this IOP took place late in the day, during which the southerly flow was approximately $5 \mathrm{~m} \mathrm{~s}^{-1}$. Three radiosonde launches captured interesting weather features. A very dry (temperature $T=10^{\circ} \mathrm{C}$, dewpoint $T_{d}=-40^{\circ} \mathrm{C}, \mathrm{RH}=2 \%$ ) layer was present at the top of the mixed layer, which later merged with a second dry layer at a higher altitude. This type of feature was unfamiliar to the students present, and the profile was later included in a skew $T$ plotting program used in other courses. The final sounding captured the weakening of the winds resulting from formation of the evening boundary layer.

Performance of the tower instruments can be affected by the wind orientation with respect to the mast. During BaSE CaMP II, a day with westerly flow was chosen for deployment to the KVSC tower. As a surface trough passed the site, the low-level wind shifted from west-southwest in the first sounding to west-northwest in the second sounding. Also, the top of the mixed layer produced a clear signal in the wind profiler data, and the depth of this signal increased as the trough passed MISS. This event and a preliminary quick-look analysis was shown to students by EOL personnel in a presentation to the Radar and Satellite Meteorology class.

Observation and physical modeling of urban airflow. Another opportunity to use the field measurements was to model and study airflow around campus buildings. One BaSE CaMP II IOP had MISS located on the SCSU campus surrounded by prominent buildings. A radiosonde was released (Fig. 3), and the wind profiler and surface station collected data throughout the flight. At the same time, students used handheld Kestrel units to record wind patterns around the maze of campus buildings. This experiment is similar to a temperature-based exercise described by Newman (2008) and also done in SCSU's Instrumentation course, but this time with the addition of MISS.

The time and publicly accessible location of the radiosonde launch attracted many visitors and observers, including meteorology majors in several 
classes, former students of the department's general education courses, and curious passersby. Weather conditions were ideal for watching the balloon's flight. Skies were completely clear, and a veering wind profile from southeast to west caused the balloon to essentially circle the MISS site, keeping it in view long after its release.

This IOP was a learning and public relations success, and the data collected became tied to the broader interest in airflow on the campus. The SCSU meteorology program operates a low-cost wind tunnel used for anemometer experiments in the Instrumentation course and to demonstrate concepts in the Atmospheric Dynamics course. It was also used for a student research project with 3D-printed models of islands. After BaSE CaMP II, a 3D model of one campus building was created and placed in the wind tunnel (Fig. 3). One of the primary questions was how well the flow could be visualized using dry ice sublimation. The conclusion was that the white model needed to be painted a darker color to provide more contrast with the white sublimate. It was also determined the model should be reduced in size to allow room for models of adjacent buildings in the tunnel. Data from the BaSE CaMP II IOP may eventually be compared to flows in the tunnel.

These four local deployments provided great variety of phenomena and the methods used to observe them. Each relied on a particular characteristic of its associated site, so the mobility of MISS was critical in creating the range of experiences.

FIXED DEPLOYMENTS. While the mobile phases took advantage of unique locations, many weather events did not require MISS to be moved from a home site. During BaSE CaMP I, the home site was a gated area adjacent to the southernmost parking lot on campus. This was a convenient location for on-campus students. Although this same site was used briefly in BaSE CaMP II for a demonstration radiosonde launch in the Physical Meteorology class, a different and more permanent home site was chosen because MISS would remain in a fixed location for three weeks. EOL personnel were not present for much of that time, and the fixed site was operated by SCSU students and faculty.

SCSU operates the Minnesota Highway Safety and Research Center in the eastern outskirts of the city. It is isolated from surrounding homes and businesses, and had a trailer to provide power and shelter for the wind profiler. One complicating aspect of this site is that escorts were required when highway training was in session (which involved police cars, ambulances, and snowplows). However, center staff was very gracious and helpful in assisting our project.

During the mobile phase, the home site was used for student training on launching radiosondes and backing up wind profiler data. There was also a fun follow-up to the BaSE CaMP I RASS experiment (see "Pilot balloon and RASS experiments" section) with a new selection of music. Once again, alternatives to the standard RASS noise failed to produce useful temperature profiles. This section describes the activities that occurred at the BaSE CaMP I and BaSE CaMP II fixed sites (Table 3).

Cold-frontal passage. Late in BaSE CaMP I, a strong cold front was forecast to pass through St. Cloud in the overnight hours of 3-4 October 2012. To capture this event for student study, an overnight IOP was declared. A single radiosonde was launched early on the evening of 3 October. After termination, the wind profiler and surface station operated unattended and continued to collect data overnight. The next morning a single postfrontal radiosonde marked the conclusion of operations.

While the postfrontal air was too dry for good quality wind profiles, the initial wind shift from southwest to west-northwest was documented across six profiles. One profile also showed the continued southwest flow aloft as the low-level front moved

TABLE 3. Intensive observing periods during the fixed deployment phase of BaSE CaMP II. All locations were at the MN Highway Safety and Research Center.

\begin{tabular}{|lccc|}
\hline ID & Time and date & Experiment & Soundings \\
\hline Foxtrot & 1400-2000 UTC 27 Oct 2014 & Prefrontal environment & 2 \\
Golf & 2300 UTC 31 Oct-0330 UTC I Nov 2014 & Inversion buildup & 3 \\
Hotel & 1700-2300 UTC 5 Nov 2014 & Steady light rain event & 3 \\
India & $1100-1700$ UTC 7 Nov 2014 & Mesoscale heavy snowband & 3 \\
Juliet & $1500-2100$ UTC 14 Nov 2014 & Air quality measurements/balloon & 1 \\
\hline
\end{tabular}




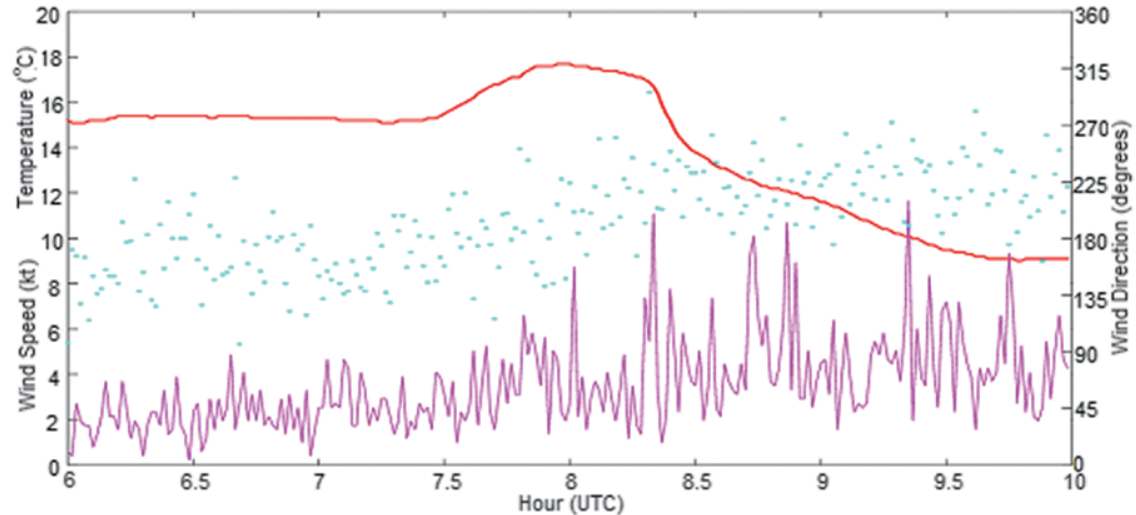

Fig. 4. Temperature ( ${ }^{\circ} \mathrm{C}$; red line), wind speed (kt, where I $\mathrm{kt} \approx 0.5 \mathrm{I} \mathrm{m} \mathrm{s}{ }^{-1}$; violet line), and direction ( ${ }^{\circ}$; cyan dots) from MISS's surface station on 4 Oct 2012. three weeks. As expected, the quality of the profiles varied with the prevailing conditions. They were particularly poor near the end of the project after the onset of colder weather and snow. However, there were several periods with excellent detailed time-height temperature cross sections, including 23 October 2014 a non-IOP day, when a frontal passage and inversion were documented for student analysis.

through. The surface measurements were even more detailed with a 1-min sampling interval. When the wind shift began, the temperature increased $3^{\circ} \mathrm{C}$ over $30 \mathrm{~min}$ before falling $9^{\circ} \mathrm{C}$ in the next 90 min (Fig. 4). This surface event was highlighted by a student presenter in the next Daily Weather Discussion class.

The two soundings showed the stark contrast between pre- and postfrontal air masses. The Wednesday evening atmosphere was well mixed and very dry in the boundary layer. A capping deck of stratocumulus was visually observed, but the balloon appears to have passed through a gap in this deck. This fact was a considerable source of discussion among the students and taught a valuable lesson about representativeness of profile observations. The air at midlevels had a deep saturated layer. On the other hand, Thursday morning's sounding revealed a shallow surface layer topped by very stable air and low-level clouds but little moisture aloft. The dataset was an excellent example of a nonprecipitating coldfrontal passage.

The student gathering for this IOP was also an opportunity to experiment with the MISS surface station's acoustic rain gauge. Syringes borrowed from the groundwater hydrology program were used to create artificial rain with calculable rain rates at a "slow" and "fast" pace. The intent was to compare the artificial rain rate to the instrument-measured value, but the MISS station's quality control (QC) algorithm rejected all but the "small" drops of the slow rain. It would be a useful exercise to determine the specific criteria that caused the measurements to be rejected by the QC algorithm.

Low-level temperature structure. At the fixed site for BaSE CaMP II, RASS was used continuously for
The high-quality RASS returns began near midnight, just before a brief rain shower. The lowestlevel temperatures decreased from $12^{\circ}$ to $9^{\circ} \mathrm{C}$, but the lapse rates remained positive until 0630 UTC (0130 LDT) and isothermal for another $5 \mathrm{~h}$. After an occluded front passed the site, temperatures below $200 \mathrm{~m}$ AGL fell, while those above started to rise. This frontal inversion reached a strength of $5^{\circ} \mathrm{C}$ over this depth. At 1700 UTC (1200 LDT), low-level temperatures increased, forming an isothermal profile within $2 \mathrm{~h}$ and positive lapse rates after that (Fig. 5). RASS proved to be an excellent tool to document the temperature evolution of this passing front.

Precipitation events. BaSE CaMP I had a good variety of weather and experiments up to the final project day, but none involved precipitation. A final BaSE CaMP I IOP was called for the evening of 5 October 2012 to launch one final radiosonde, giving students a last opportunity to see MISS in operation. As students watched the radiosonde ascent, the MISS surface station began reporting traces of precipitation. Some

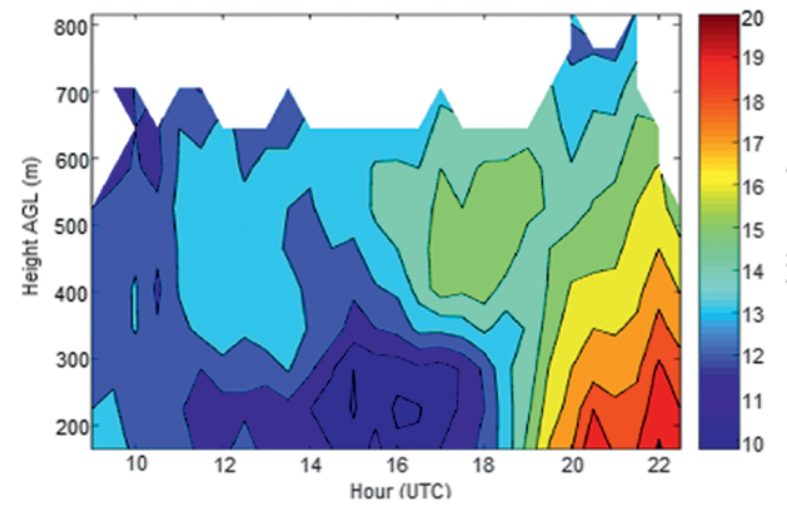

FIG. 5. Time-height section of temperature $\left({ }^{\circ} \mathrm{C}\right)$ retrieved from RASS on 23 Oct 2014. 
students came inside the MISS trailer when light graupel began falling. The addition of a snowfall event, particularly one occurring in less than ideal conditions, further improved the variety of measurements collected during the 1-week deployment.

Similarly, the precipitation events during BaSE CaMP II occurred late in the project, during operations at the fixed site. On 5 November 2012, steady rain fell from 1400 to 2400 UTC and $0.19 \mathrm{in} .(0.48 \mathrm{~cm})$ accumulated. Late in the event, this rain began to mix with a few snowflakes. Three radiosondes were launched at 3-h intervals, the last being near the time of the mixed precipitation.

The wind profiler's radar measurements provided an excellent example of a cold-cloud rain event. Figure $6 \mathrm{a}$ shows the radar bright band in a time-height cross section of signal-to-noise ratio (SNR), indicating the melting layer from snow to rain. Initially it is near $1 \mathrm{~km}$ AGL with a minimum in SNR just below. The layer descends throughout the period, consistent with later mixed precipitation observed at the surface. The Doppler velocities also show the transition in precipitation fall speed from gently falling snow to rapidly descending raindrops. The Doppler spectral widths also increase, which for the vertically pointing beam is primarily due to a mixture of fall velocities and therefore droplet diameters.

BaSE CaMP II continued through the first half of November, and it was hoped that the first significant snowfall of the season would occur and be documented. The forecast for 10 November 2014 looked promising with St. Cloud just north of a mesoscale band and in good position for comparison to other observations, such as NWS radiosondes and radar. However, subsequent forecasts for 10 November gradually shifted the action northward until the snow maximum was located directly over St. Cloud.

An initial radiosonde was launched at 1100 UTC, coinciding with the morning NWS synoptic release, although snowfall was light at this time. Later soundings at 1400 and 1700 UTC were released when the snowfall rates were heaviest. As with the steady rain event, wind profiler radar measurements provide excellent microphysical detail. Figure $6 \mathrm{~b}$ shows the same variables as in the 5 November event, but the structure is very different.

The slower snowfall produces a very clear fallstreak signature, as high signal-to-noise ratios occur at lower altitudes, especially later in the event. This characteristic has been seen in airborne radar observations of major snow events (Rauber et al. 2014). Fall speeds increase little near the surface, but there are variations in the Doppler spectral width. While widths are broader at upper levels (perhaps as a result of wind, an effect called beam broadening), near 2,000 $\mathrm{m}$ AGL the widths are very small, suggesting uniform fall speeds. Just above the surface, the event initially has narrow widths, but these become broader late in the event. This is consistent with theoretical predictions of well-formed snow crystals becoming more heavily rimed (Rogers and Yau 1989).

Consistent with the late model runs, St. Cloud was in the region with the highest snowfall totals. Figure 7 shows the area distribution of the snow event and an example of the accumulation in St. Cloud. As
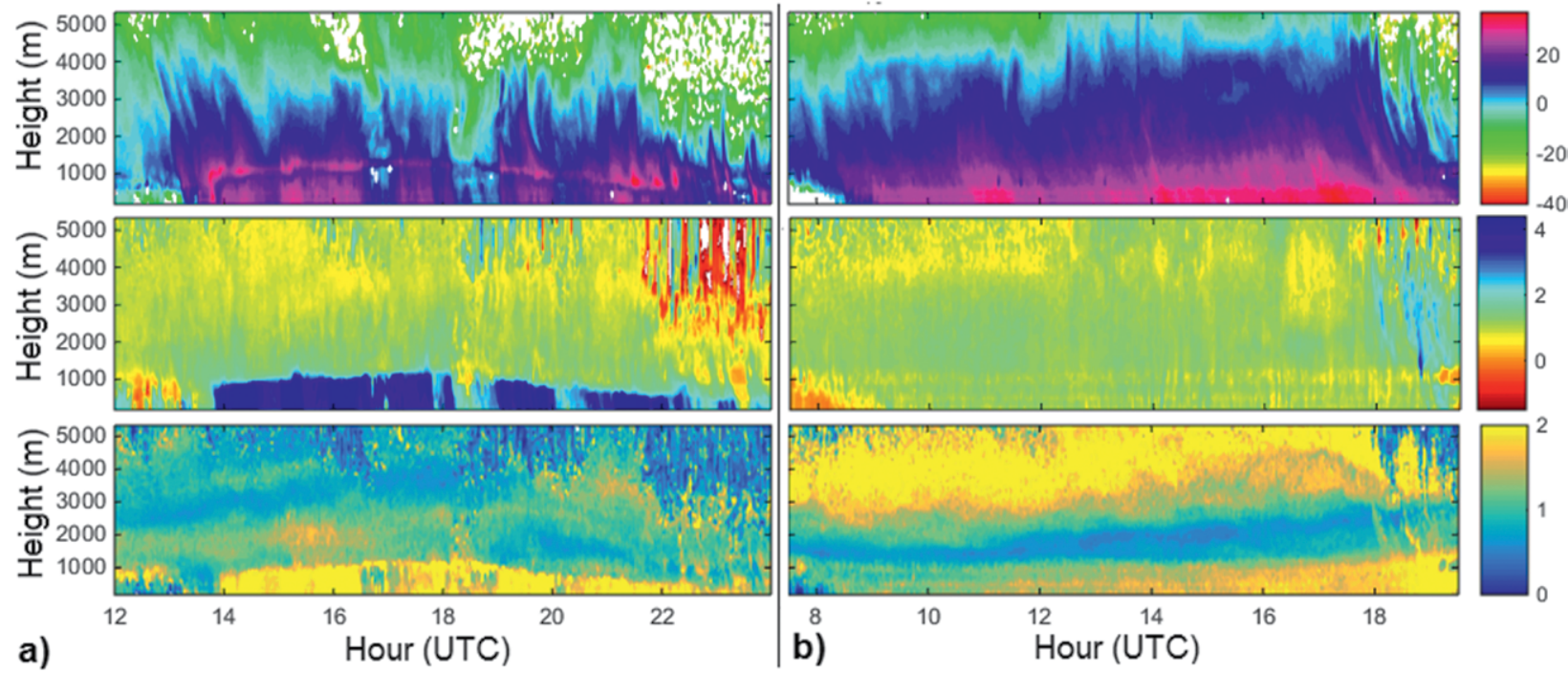

a)

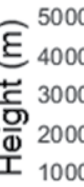
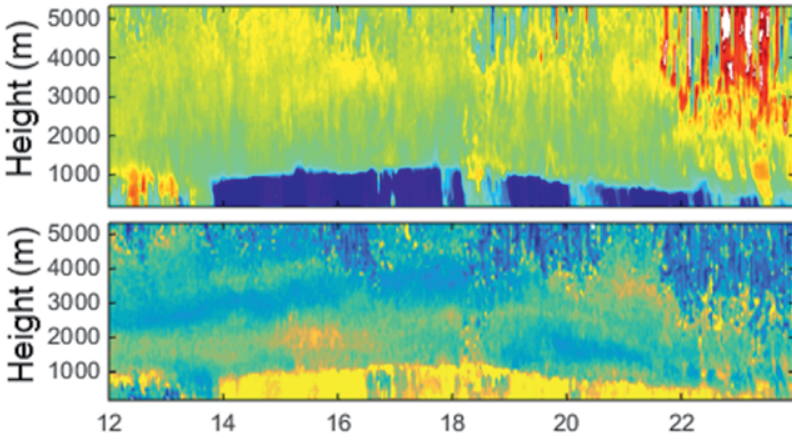

Hour (UTC)

b)

Hour (UTC)

FIG. 6. Time-height diagrams of (top) signal-to-noise ratio, (middle) radial velocity, and (bottom) spectral width from (a) 5 and (b) 10 Nov 2014. 


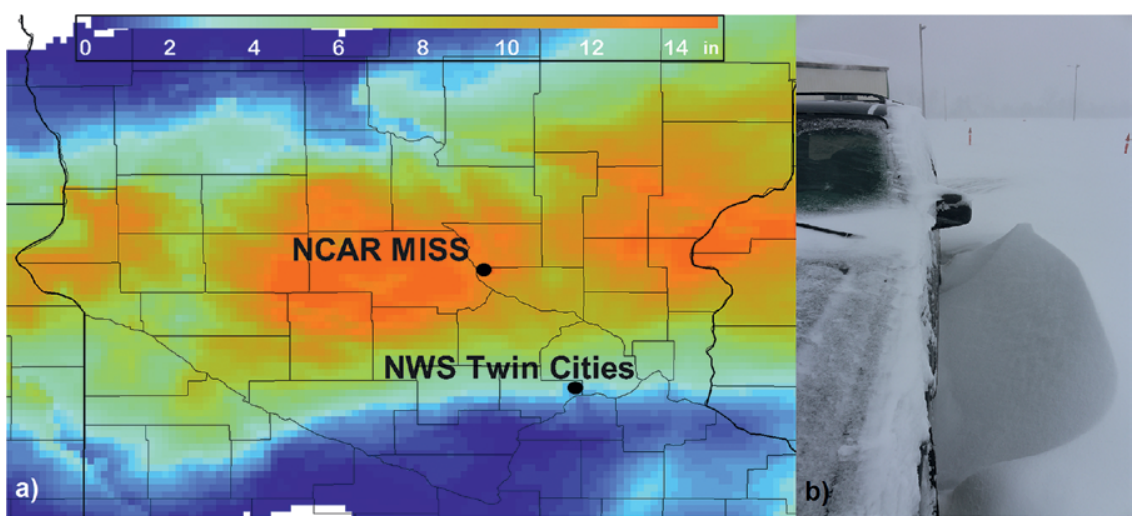

FIG. 7. (a) Unidata IDV display of storm-total snowfall (in.; I in. $\approx 2.54 \mathrm{~cm}$ ) over central MN on 9-10 Nov 2014 (source: National Operational Hydrologic Remote Sensing Center). (b) Drifting snow on the windward side of a 1997 Ford Explorer.

with many bands, there was a sharp gradient (in this case on the southern edge, including the Twin Cities metropolitan area) where totals varied from 1 to 6 in. $(2.5$ to $15.25 \mathrm{~cm})$ over a short distance. In the core, maximum snowfall exceeded 12 in. $(30.5 \mathrm{~cm})$, with 13.5 in. $(34.3 \mathrm{~cm})$ measured near the MISS location. This snow was accompanied by strong winds, which caused major drifting. Classes at SCSU were canceled later in the day. The significance of this event makes it a valuable addition to the BaSE CaMP datasets.

PUBLIC OUTREACH. NSF educational deployments require interaction with students, faculty, and public groups outside atmospheric science departments. During both years of BaSE CaMP, public outreach activities were emphasized. There was interesting variation in both the target groups and how the engagement occurred.

BaSE CaMP I took advantage of the proximity of Technical High School in St. Cloud with a 2-h outreach visit. The 24 high school students taking Advanced Placement Physics learned from NCAR staff about meteorology in general, the structure of the atmosphere, and the role that measurements and models play in forecasts and research.
It was a beautiful day for the students to be out of their classroom. They saw the instruments of the MISS weather station, data from the wind profiler and RASS, and helped with a radiosonde release (Fig. 8).

The radiosonde detected very dry air just above the mixed layer, which drove home the explanation of both boundary layer mixing and the layered nature of the atmosphere. Students showed the greatest interest in things they could see and touch, such as the propeller-vane anemometer and the radiosonde and balloon before launch. While there was no school visit in BaSE CaMP II, a pair of science teachers from Sauk Rapids-Rice Senior High School arranged a trip to the base site. They observed the steps of radiosonde prelaunch preparation and obtained sounding data for later use in their classrooms.

While the MISS kindergarten to grade $12(\mathrm{~K}-12)$ visits were interactive and hands on, classroom and auditorium presentations by EOL personnel included more information on the instrumentation and how it has been used. Classroom lectures were presented for Radar and Satellite Meteorology courses. A BaSE

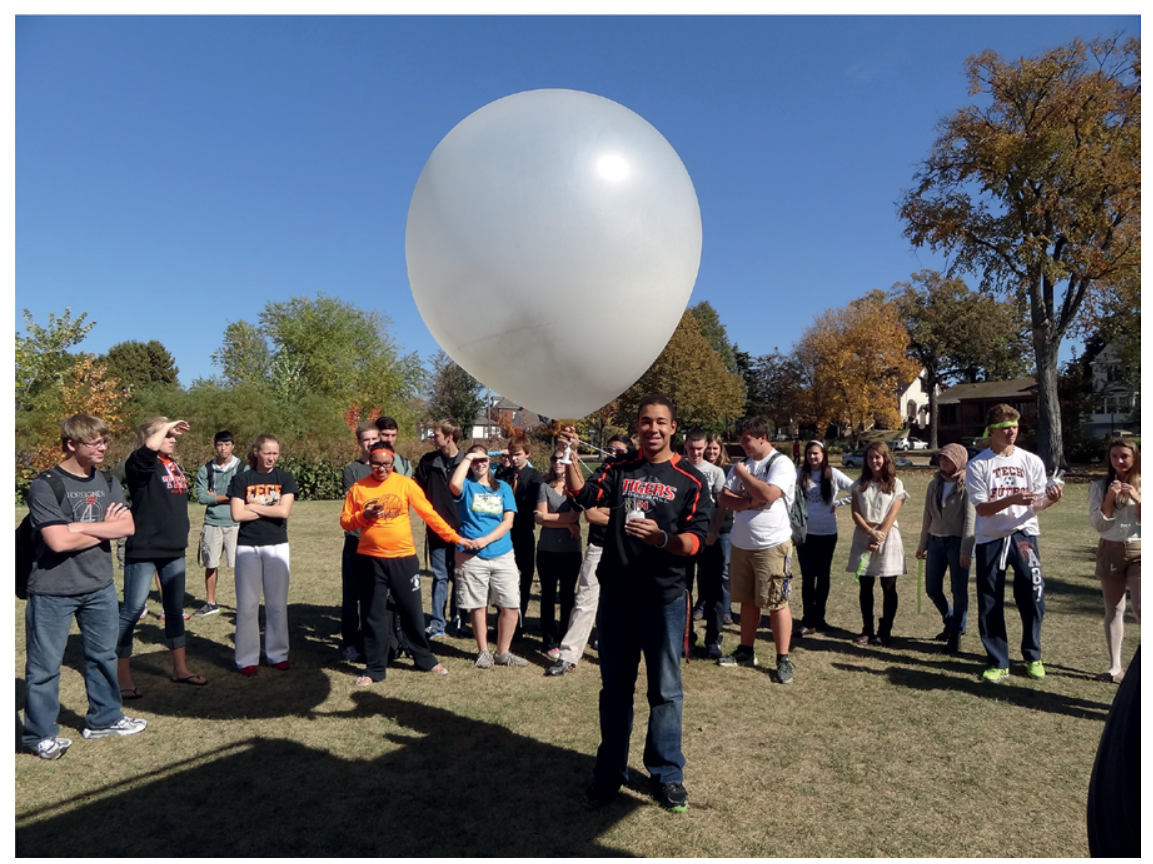

Fıg. 8. Students from Technical High School prepare to launch a radiosonde during BaSE CaMP I. 
CaMP I evening seminar was open to the public and described the use of radiosondes ("weather balloons") in multiple large field campaigns. The presentation's attendance included 35 students from a large class for atmospheric science nonmajors, who received extra credit for their participation. BaSE CaMP II operations began immediately after the department's annual Northern Plains Winter Storm Conference. This had a keynote presentation by Greg McFarquahar of the University of Illinois UrbanaChampaign, who discussed the Profiling of Winter Storms (PLOWS) project. Since MISS was involved in PLOWS, a BaSE CaMP II motivated complementary talk presented the latest developments in MISS and ISS activities. Conference attendees included forecasters from the NWS and the private sector, and students from other universities. All learned about NSF and EOL resources, as well as a range of winter weather phenomena.

In addition to public outreach, the project provided opportunities to develop better educational strategies and activities. For example, since the compasses used in the BaSE CaMP I IOP Bravo balloon tracking experiment were not ideal, EOL purchased a low-cost sextant to use for the same exercise in BaSE CaMP II. This was tested during one of the final launches (Fig. 9). The new addition to the MISS trailer is expected to be used during future visits to $\mathrm{K}-12$ schools.

CLASSROOM DATA USE. A frequently cited reason for not requesting NSF educational facilities

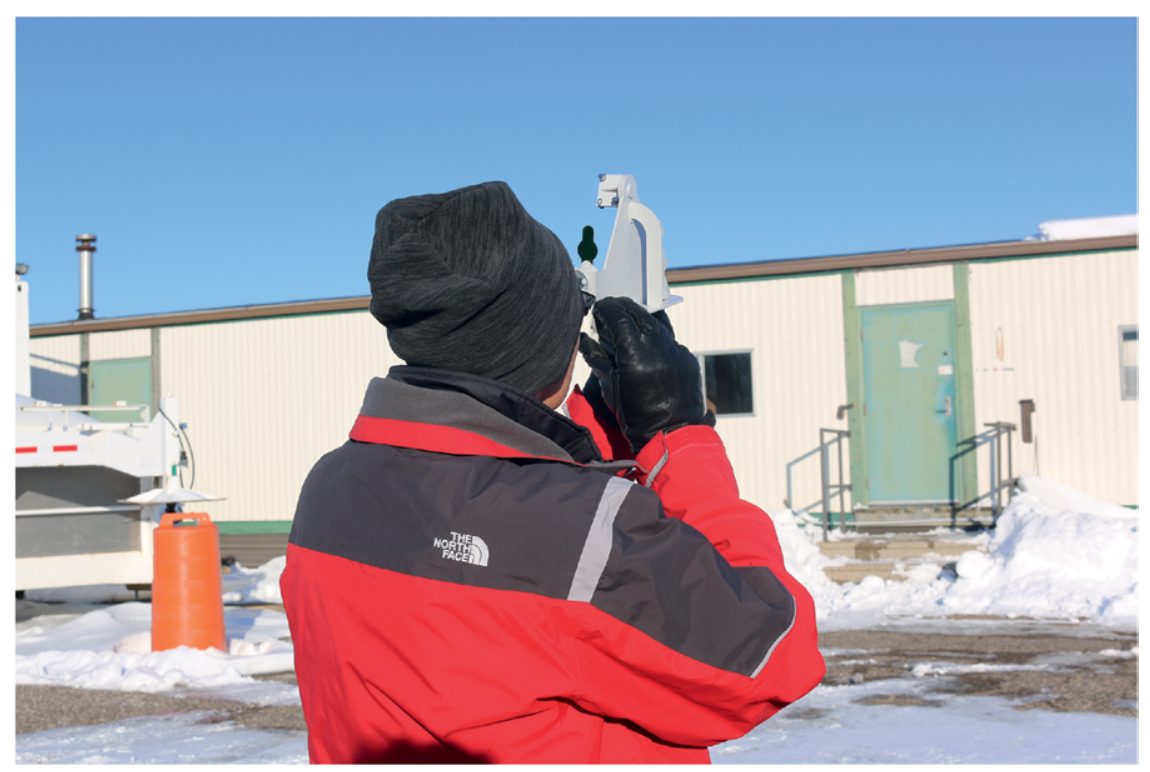

Fig. 9. A BaSE CaMP II balloon is tracked from the ground using MISS's new sextant. other than the DOW is difficulty in incorporating these deployments into course work. This section describes how BaSE CaMP data were incorporated into five different courses after the observational phase concluded. Since nearly all of the following assignments and lectures already existed with generic or invented data, it was a simple matter to revise them to relate to the deployments at SCSU.

BaSE CaMP I was primarily intended to support the Radar and Satellite Meteorology course. Students were required to attend two events (IOPs or presentations), and concepts and data were incorporated into later portions of the course. The curriculum already covers wind profiler operation (particularly the plotting of wind vectors) and RASS principles, so exam questions were formulated in the context of BaSE CaMP I. Students are also required to write a paper and to prepare an oral presentation reviewing a recent article on satellite meteorology. They were given the option of using the BaSE CaMP I deployments as topics instead.

The SCSU Atmospheric Dynamics course (first semester) concludes with a unit on boundary layer dynamics. Problems and projects in this course were modified to use BaSE CaMP I observations instead of generic numbers. For example, in one homework problem students were given the sounding data from IOP Bravo at the airport and from IOP Echo on the SCSU campus. Using wind measurements near the surface and $100 \mathrm{~m} \mathrm{AGL}$, their task was to calculate roughness lengths and to compare them to theoretical values (Stull 1988). Agreement turned out to be excellent. Students also developed their programming skills writing a MATLAB routine to calculate Richardson number profiles from radiosonde observations. For this, the first and last soundings from the BaSE CaMP I inversion breakup event (IOP Alpha) were used, between which the boundary layer height changes by nearly a kilometer.

A new course taught the same semester as BaSE CaMP I was Meteorological Analysis Software. In addition to scripting and command line programs such as General 
TABLE 4. Student quotes on the BaSE CaMP I and II educational experience.

"The most interesting thing to me probably was that NCAR hires student workers to assist in their research projects, which I will definitely apply for when the time comes."

"Using the radiosondes, surface observations, and field observations to put together all the pieces of data in regards to the warming temperatures and the wind picking up was a great hands-on way to observe local effects of a morning temperature inversion."

"This was the highlight of my year so far."

"The MISS visit was a great experience, because I personally don't have a lot of instrumental experience, and the MISS got me very excited for my future as a meteorologist. My favorite part of the MISS visit was actually seeing the radiosonde launch and watching its observations of the upper atmosphere being reached."

“I loved the fact that students were invited to do hands-on work with the MISS. Field research is something I'm striving to do in my career so to get some of that experience working with instruments is extremely invaluable to me. Not to mention it was really fun to work with!"

"I plan on going into research when I am done with school, so it was enlightening to see how data is collected in the field. Although I don't have any ambition to launch another weather balloon (I'm terrified of balloons), it was a one-of-a-kind experience to be a part of."

"This experience helped me better understand the field work that was required to be able to review past forecasts."

"The fact that the instruments were set up near enough to campus, that NCAR and SCSU researchers and staff were readily available to train students, and that the project was integrated into our class discussions made it a very convenient and enriching experience."

"The Basecamp field experience in an IOP gave me a taste of field work and IOPs, preparing me for my own research as a master's student at the University of Wyoming. I gained experience using instrumentation to observe a meteorological phenomenon, which improved my forecasting skills."

"I think being in the same environment where the data is being collected can play a very important role in understanding what is causing the current weather situation. . . Seeing the data come in live while standing in the same conditions is an experience you can't get from looking at graphs or maps in a textbook or online."

Meteorological Package (GEMPAK) and Grid Analysis and Display System (GrADS), the class extensively used Unidata's Integrated Data Viewer (IDV), which supports data from EOL instrumentation quite well. The range of MISS instruments provided data for varied practice exercises and numerous display exercises, including skew $T$ diagrams, profiler wind vector barbs, and surface point observations. The handheld Kestrel student measurements were also incorporated.

BaSE CaMP II was primarily intended to support the SCSU Physical Meteorology class. The radar wind profiler operations supported the radiative transfer unit where principles of radiation and scattering are covered, while data from the precipitation IOPs were used in the cloud physics unit. Measurements from BaSE CaMP I were also used with a brief unit on meteorological acoustics. Physical Meteorology students were required to complete two term projects incorporating a range of topics. One of the options was to plot and interpret the RASS temperature profiles from the BaSE CaMP I SCSU airport deployment (IOP Bravo). Finally, most students taking Physical Meteorology would take Instrumentation the following semester, so the entire class traveled to MISS for a radiosonde launch.

PROJECT EVALUATION. An important metric used by NSF is the number of students that are reached by an educational deployment. In BaSE CaMP I, 82 students interacted with MISS, provided field support, or attended outreach activities. Approximately half of these students encountered the project in more than one class or venue. BaSE CaMP II also reached 80 students, though more students were reached through classroom and conference presentations.

Feedback from the large majority of these students was very positive. Table 4 presents quotes made both immediately after each project and several 
years afterward. The most common concern was that despite the effort to vary timing and locations of IOPs, some students were unable to participate in any of the field experiments outside normal classroom hours. This was a greater concern for the shorter (1 week) BaSE CaMP I deployment.

The benefits of the BaSE CaMP projects extend beyond the deployment period and immediate coursework. Datasets from 17 diverse weather events remain available to be used in future courses and in student or faculty projects. Such a project occurred in summer 2014, when two SCSU students joined three BaSE CaMP principal investigator (PIs) in conducting Weather Research and Forecasting (WRF) Model simulations of the cold pool breakup event (IOP Alpha). Simulation results and their applications to forecasting were summarized in a poster presented at the American Meteorological Society's (AMS) 16th Conference on Mountain Meteorology (2014). This was a very positive outcome for the student's education and experience.

Furthermore, experience with MISS instrumentation led to future opportunities for participants (both students and PIs). The latest modular version of the ISS (a nonmobile and more sophisticated variant of MISS) participated in the large field project called Deep Propagating Gravity Wave Experiment over New Zealand (DEEPWAVE; Fritts et al. 2016). The ISS collected atmospheric profiles upwind of the gravity wave source (the Southern Alps). In the same region, SCSU was collecting stereo-photogrammetric images of the upstream clouds for DEEPWAVE. A student who was familiar with ISS instruments because of BaSE CaMP I took on a dual role by also assisting the ISS team. She subsequently presented her DEEPWAVE research at meetings sponsored by the American Geophysical Union and AMS (Osborne and Billings 2015).

Even more opportunities were available for the Plains Elevated Convection at Night (PECAN) field campaign (Geerts et al. 2017). For two months, three ISSs were deployed at separate fixed locations and MISS was used as a mobile facility. Student assistants and operators were chosen from a pool of U.S. and

international applicants, and those with previous ISS and MISS experience had an advantage. Three SCSU BaSE CaMP students were hired to help with PECAN, one of whom was given the role to lead a student team (Fig. 10).

CONCLUSIONS. In summary, the use of MISS through the NSF educational deployment program is an excellent way to fulfill the goals described at the end of the introduction, and similar future deployments can be valuable at other institutions. With the ability to study many different types of weather conditions, there were frequent deployment and operational periods allowing for more student field participation than would otherwise have occurred. Since the dataset was so diverse, it was used in far more courses than the primary one identified in both proposals, and it is still available to be used in projects that could ultimately be presented in many different AMS specialty conferences. Finally, numerous other individuals, such as high school students and NWS employees, learned more about this and other work done by SCSU and EOL.

ACKNOWLEDGMENTS. The authors acknowledge NSF for providing funding to NCAR (0753581) and the local residents of St. Cloud who allowed deployment on their properties, especially SCSU's MN Highway Safety and Research Center. SCSU's staff was incredibly helpful with multiple coordination and troubleshooting issues. The authors also thank Allison Rockwell of the NCAR Earth Observing Laboratory for the helpful comments on this manuscript as well as two anonymous reviewers. NCAR is managed by the University Corporation for Atmospheric Research and sponsored by NSF. 


\section{REFERENCES}

Barrett, D. J., and J. E. Woods, 2012: Using the amazing atmosphere to foster student learning and interest in meteorology. Bull. Amer. Meteor. Soc., 93, 315-323, https://doi.org/10.1175/BAMS-D-11-00020.1.

Bell, M. M., and Coauthors, 2015: The Hawaiian Educational Radar Opportunity (HERO). Bull. Amer. Meteor. Soc., 96, 2167-2181, https://doi.org/10.1175 /BAMS-D-14-00126.1.

Biggerstaff, M. I., and Coauthors, 2005: The Shared Mobile Atmospheric Research and Teaching radar: A collaboration to enhance research and teaching. Bull. Amer. Meteor. Soc., 86, 1263-1274, https://doi .org/10.1175/BAMS-86-9-1263.

Borys, R. D., and M. A. Wetzel, 1997: Storm Peak Laboratory: A research, teaching, and service facility for the atmospheric sciences. Bull. Amer. Meteor. Soc., 78, 2115-2123, https://doi.org/10.1175/1520 -0477(1997)078<2115:SPLART>2.0.CO;2.

Brunkow, D., V. N. Bringi, P. C. Kennedy, S. A. Rutledge, V. Chandrasekar, E. A. Mueller, and R. K. Bowie, 2000: A description of the CSUCHILL National Radar Facility. J. Atmos. Oceanic Technol., 17, 1596-1608, https://doi.org/10.1175/1520 -0426(2000)017<1596:ADOTCC>2.0.CO;2.

Brunskill, J., and C. Jones, 2011: The Bloomsburg Weather Viewer: A resource for integrating webcam and local weather station data into the introductory meteorology classroom. Bull. Amer. Meteor. Soc., 92, 956-962, https://doi.org/10.1175/2011BAMS3131.1.

Capella, R. J., and E. L. Morehead, 2018: Investigating Appalachian-induced fine-scale frontal features during SEAR-MAR. 17th Annual Student Conf., Austin, TX, Amer. Meteor. Soc., S170, https:// ams.confex.com/ams/98Annual/webprogram /Paper338381.html.

Cassano, J. J., 2014: Weather Bike: A bicycle-based weather station for observing local temperature variations. Bull. Amer. Meteor. Soc., 95, 205-209, https://doi.org/10.1175/BAMS-D-13-00044.1.

Cohn, S. A., J. Hallett, and D. Koracin, 1997: Blending education and research in atmospheric scienceA case study. Phys. Today, 50, 34-39, https://doi .org/10.1063/1.881891.

—, — , and J. M. Lewis, 2006: Teaching graduate atmospheric measurement. Bull. Amer. Meteor. Soc., 87, 1673-1678, https://doi.org/10.1175/BAMS $-87-12-1673$.

Croft, P. J., and J. Ha, 2014: The undergraduate "consulting classroom": Field, research, and practicum experiences. Bull. Amer. Meteor. Soc., 95, 1603-1612, https://doi.org/10.1175/BAMS-D-13-00045.1.
Etherton, B. J., S. C. Arms, L. D. Oolman, G. M. Lackmann, and M. K. Ramamurthy, 2011: Using operational and experimental observations in geoscience education. Bull. Amer. Meteor. Soc., 92, 477-480, https://doi.org/10.1175/2010BAMS3045.1.

Evans, C., and Coauthors, 2012: The Pre-Depression Investigation of Cloud-Systems in the Tropics (PREDICT) field campaign: Perspectives of early career scientists. Bull. Amer. Meteor. Soc., 93, 173187, https://doi.org/10.1175/BAMS-D-11-00024.1.

Fritts, D. C., and Coauthors, 2016: The Deep Propagating Gravity Wave Experiment (DEEPWAVE): An airborne and ground-based exploration of gravity wave propagation and effects from their sources throughout the lower and middle atmosphere. Bull. Amer. Meteor. Soc., 97, 425-453, https://doi .org/10.1175/BAMS-D-14-00269.1.

Geerts, B., and Coauthors, 2017: The 2015 Plains Elevated Convection at Night field project. Bull. Amer. Meteor. Soc., 98, 767-786, https://doi.org/10.1175/BAMS -D-15-00257.1.

Godfrey, C. M., B. S. Barrett, and E. S. Godfrey, 2011: Severe weather field experience: An undergraduate field course on career enhancement and severe convective storms. J. Geosci. Educ., 59, 111-118, https:// doi.org/10.5408/1.3604823.

Hopper, L. J., C. Schumacher, and J. P. Stachnik, 2013: Implementation and assessment of undergraduate experiences in SOAP: An atmospheric science research and education program. J. Geosci. Educ., 61, 415-427.

Houston, A. L., B. Argrow, J. Elston, J. Lahowetz, E. W. Frew, and P. C. Kennedy, 2012: The Collaborative Colorado-Nebraska Unmanned Aircraft System Experiment. Bull. Amer. Meteor. Soc., 93, 39-54, https://doi.org/10.1175/2011BAMS3073.1.

Illari, L., and Coauthors, 2009: "Weather in a tank"Exploiting laboratory experiments in the teaching of meteorology, oceanography, and climate. Bull. Amer. Meteor. Soc., 90, 1619-1632, https://doi .org/10.1175/2009BAMS2658.1.

Kahl, J. D. W., and J. G. Cerón, 2014: Faculty-led study abroad in atmospheric science education. Bull. Amer. Meteor. Soc., 95, 283-292, https://doi.org/10.1175 /BAMS-D-13-00051.1.

Kelsey, E., C.-M. Briedé, K. O’Brien, T. Padham, M. Cann, L. Davis, and A. Carne, 2015: Blown away: Interns experience science, research, and life on top of Mount Washington. Bull. Amer. Meteor. Soc., 96, 1533-1543, https://doi.org/10.1175/BAMS-D-13-00195.1.

Knupp, K. R., J. Walters, and E. W. McCaul, 2000: Doppler profiler observations of Hurricane Georges at landfall. Geophys. Res. Lett., 27, 3361-3364, https:// doi.org/10.1029/1999GL011260. 
Kristovich, D. A. R., and Coauthors, 2017: The Ontario Winter Lake-effect Systems field campaign: Scientific and educational adventures to further our knowledge and prediction of lake-effect storms. Bull. Amer. Meteor. Soc., 98, 315-332, https://doi .org/10.1175/BAMS-D-15-00034.1.

Lee, T., and S. F. J. De Wekker, 2016: Estimating daytime planetary boundary layer heights over a valley from rawinsonde observations at a nearby airport: An application to the Page Valley in Virginia, United States. J. Appl. Meteor. Climatol., 55, 791-809, https:// doi.org/10.1175/JAMC-D-15-0300.1.

Lundquist, J. K., and Coauthors, 2017: Assessing state-of-the-art capabilities for probing the atmospheric boundary layer: The XPIA field campaign. Bull. Amer. Meteor. Soc., 98, 289-314, https://doi .org/10.1175/BAMS-D-15-00151.1.

Milrad, S. M., and C. G. Herbster, 2017: Mobile radar as an undergraduate education and research tool: The ERAU C-BREESE field experience with the Doppler on Wheels. Bull. Amer. Meteor. Soc., 98, 1931-1948, https://doi.org/10.1175/BAMS-D-15-00281.1.

Newman, S. B., 2008: A new laboratory exercise to study microscale spatial temperature changes on a university campus. Bull. Amer. Meteor. Soc., 89, 1835-1840, https://doi.org/10.1175/2008BAMS2417.1.

Osborne, T. C., and B. J. Billings, 2015: Coastal timelapse stereo photogrammetry during DEEPWAVENew Zealand. 13th Symp. on the Coastal Environment, Phoenix, AZ, Amer. Meteor. Soc., 4.6, https:// ams.confex.com/ams/95Annual/webprogram /Paper263045.html.

Parsons, D., and Coauthors, 1994: The Integrated Sounding System: Description and preliminary observations from TOGA COARE. Bull. Amer. Meteor. Soc., 75, 553-567, https://doi.org/10.1175/1520 -0477(1994)075<0553:TISSDA >2.0.CO;2.

Rajewski, D. A., and Coauthors, 2013: Crop Wind Energy Experiment (CWEX): Observations of surface-layer, boundary layer, and mesoscale interactions with a wind farm. Bull. Amer. Meteor. Soc., 94, 655-672, https:/doi.org/10.1175/BAMS-D-11-00240.1.

Rauber, R. M., and Coauthors, 2007: In the driver's seat: RICO and education. Bull. Amer. Meteor. Soc.,
88, 1929-1937, https://doi.org/10.1175/BAMS-88 $-12-1929$.

, M. K. Macomber, D. M. Plummer, A. A. Rosenow, G. M. McFarquhar, B. F. Jewett, D. Leon, and J. M. Keeler, 2014: Finescale radar and airmass structure of the comma head of a continental winter cyclone: The role of three airstreams. Mon. Wea. Rev., 142, 42074229, https://doi.org/10.1175/MWR-D-14-00057.1.

Richardson, Y., P. Markowski, J. Verlinde, and J. Wurman, 2008: Integrating classroom learning and research: The Pennsylvania Area Mobile Radar Experiment (PAMREX). Bull. Amer. Meteor. Soc., 89, 1097-1101, https://doi.org/10.1175 /2007BAMS2567.1.

Roebber, P. J., 2005: Bridging the gap between theory and applications: An inquiry into atmospheric science teaching. Bull. Amer. Meteor. Soc., 86, 507-517, https://doi.org/10.1175/BAMS-86-4-507.

Rogers, R. R., and M. K. Yau, 1989: A Short Course in Cloud Physics. Butterworth-Heinemann, 290 pp.

Schroeder, J. L., and C. C. Weiss, 2008: Integrating research and education through measurement and analysis. Bull. Amer. Meteor. Soc., 89, 793-798, https://doi.org/10.1175/2008BAMS2287.1.

Shapiro, A., P. M. Klein, S. C. Arms, D. Bodine, and M. Carney, 2009: The Lake Thunderbird Micronet project. Bull. Amer. Meteor. Soc., 90, 811-823, https:// doi.org/10.1175/2008BAMS2727.1.

Stull, R. B., 1988: An Introduction to Boundary Layer Meteorology. Kluwer Academic, 666 pp.

Toth, M., E. Jones, D. Pittman, and D. Solomon, 2011: DOW radar observations of wind farms. Bull. Amer. Meteor. Soc., 92, 987-995, https://doi .org/10.1175/2011BAMS3068.1.

Windham, T. L., A. J. Stevermer, and R. A. Anthes, 2004: SOARS: An overview of the program and its first 8 years. Bull. Amer. Meteor. Soc., 85, 42-47, https://doi .org/10.1175/BAMS-85-1-42.

Wurman, J., J. Straka, E. Rasmussen, M. Randall, and A. Zahrai, 1997: Design and deployment of a portable, pencil-beam, pulsed, 3-cm Doppler radar. J. Atmos. Oceanic Technol., 14, 1502-1512, https:/doi .org/10.1175/1520-0426(1997)014<1502:DADOAP $>2.0 . \mathrm{CO} ; 2$. 